DOI: https://doi.org/10.24867/16AM07Sovili

\title{
ANALIZA I OSNOVE ISPITIVANJA TEKSTILNIH MATERIJALA NOSEĆIH SLOJEVA TRAKA TRAKASTIH TRANSPORTERA
}

\section{ANALYSIS AND BASICS OF TESTING TEXTILE MATERIALS OF CONVEYOR BELT CARCASS}

\author{
Ružica Sovilj, Nikola Ilanković, Fakultet tehničkih nauka, Novi Sad
}

\begin{abstract}
Oblast - MAŠINSTVO
Kratak sadržaj - U ovom radu dat je pregled osobina prirodnih i sintetičkih vlakana koji se koriste kao noseći slojevi traka trakastih transportera, kao i uticaj različitih vrsta opterećenja na zamor materijala. Opisan je uticaj spoljašnjih uslova kao što su temperatura i vlaga na pojavu zamora kod tekstilnih materijala i kompozitnih struktura, kao $i$ uticaj životne sredine. Predstavljene su različite metode ispitivanja tekstilnih kompozita na zamor.
\end{abstract}

Ključne reči: tekstil, zamor, otkaz, naizmenično opterećenje, kompozitni materijali, matrica

Abstract - This paper provides an overview of the properties of natural and synthetic fibers which are used for conveyor belt carcass, as well as the influence of different types of loads on material fatigue. The influence of external conditions such as temperature and humidity on the occurrence of fatigue in textile materials and composite structures, as well as the influence of the environment are described. Different methods of fatigue testing of textile composites are presented.

Keywords: textile, fatigue, failure, cyclic loading, composite materials, matrix

\section{UVOD}

Tekstilni materijali se najčešće koriste kao noseći slojevi traka trakastih transportera, koji prenose sile koje se javljaju pri kretanju. Fleksibilnost i svestranost tekstilnih materijala mogu da dovedu do oštećenja ove ili one vrste. Oštećenja, koja se pojavljuju u vidu rupa na odevnim predmetima ili istrošenim ivicama radnih uniformi, predmeti su prethodnih istraživanja. Međutim, njihov značaj u inženjerstvu često je marginalizovan zbog ograničene primene u praksi. Pojavom tehničkih tekstilnih materijala, gde njihova elastičnost i izdržljivost prevazilaze normalnu izdržljivost i habanje, dublje razumevanje oštećenja tekstilnih materijala postalo je suštinski bitno za dizajn i proizvodnju produkata izrađenih od tekstilnih materijala.

Da bi se razumelo oštećenje na tkanini ili u strukturi tkanine, temeljna istraživanja se vraćaju na osnovni nivo, tj. da je vlakno sastavni gradivni element bilo kog proizvoda napravljenog od tekstilnog materijala.

\section{NAPOMENA:}

Ovaj rad proistekao je iz master rada čiji mentor je bio dr Dragan Živanić, vanr. prof.
Prirodne ili veštački stvorene osobine tekstilnih vlakana određuju čvrstoću, jednolikost (uniformnost), fleksibilnost, izdržljivost i na kraju i sam performans vlakna. Dakle da bi se razumeo nedostatak materijala, mora se posmatrati nedostatak jednog vlakna.

\section{ZAMOR PRI ISTEZANJU TEKSTILNIH VLAKANA}

PET vlakna se najviše koriste i proizvode (uključujući i prirodna vlakna) širom sveta. Poliamidna vlakna (PA) su prva proizvedena sintetička vlakna, druga po proizvodnji i upotrebi među sintetičkim vlaknima. Obe vrste su pronašle široku primenu u proizvodnji odeće $i \mathrm{u}$ tehničkim strukturama visokih performansi kao što su proizvodnja pneumatika, traka trakastih transportera itd. Naravno, postoje i mnogi drugi primeri. Želja da se izbegne neočekivana pojava otkaza vlakna usled zamora je očigledna. Ove vrste vlakana doživljavaju otkaz usled zamora pod određenim vrstama naizmeničnog opterećenja zatezanjem. Karakterističan oblik loma materijala, koji se javi prilikom otkaza usled zamora, može se upotrebiti za dijagnostiku i dozvoljava uvid u mehanizme koji kontrolišu ovaj vid ponašanja. Razumevanje procesa zamora materijala u ovim vlaknima sugeriše način eliminacije ili smanjenja verovatnoće nastanka nepredviđenih otkaza.

Otkazi usled zamora dve najveće grupe sintetičkih vlakana poliamida (PA) i poliestera (PET) su predmet istraživanja, uz spominjanje polietilen naftalata $(\mathrm{PEN})$ koji se ponaša slično PET vlaknima. Svojstvo koje je najuočljivije kod otkaza usled zamora ove vrste vlakna jeste njegov oblik preloma, koji je sam po sebi svojstven i razlikuje se od preloma nastalog pod uticajem klasičnog zatezanja ili puzanja. Slika 1 prikazuje odgovarajuće krajeve vlakna PA66 koja su prekinuta usled dostizanja napona loma. Strelice prikazuju mesto stvaranja početne pukotine.

Vrste otkaza vlakna prikazana na slici 1 karakteristične su za otkaze nastale zatezanjem i puzanjem kod vlakana PA6, PA66, PET i PEN. Dva uporedna prikaza pokidanih krajeva su veoma slična u izgledu. Postoje dve oblasti koje predstavljaju očigledna mesta za napredak pukotine [1]. Od regiona inicijalne pukotine postoji zakošena zona koja nastaje usled faze sporog napretka pukotine tokom koje plastična deformacija ispred pukotine dovodi do njenog širenja. Noseći poprečni presek vlakna se smanjuje širenjem pukotine $i$ na kraju dolazi do otkaza na nekontrolisan način, što dovodi do zone kidanja koja je normalna na osu vlakna. 


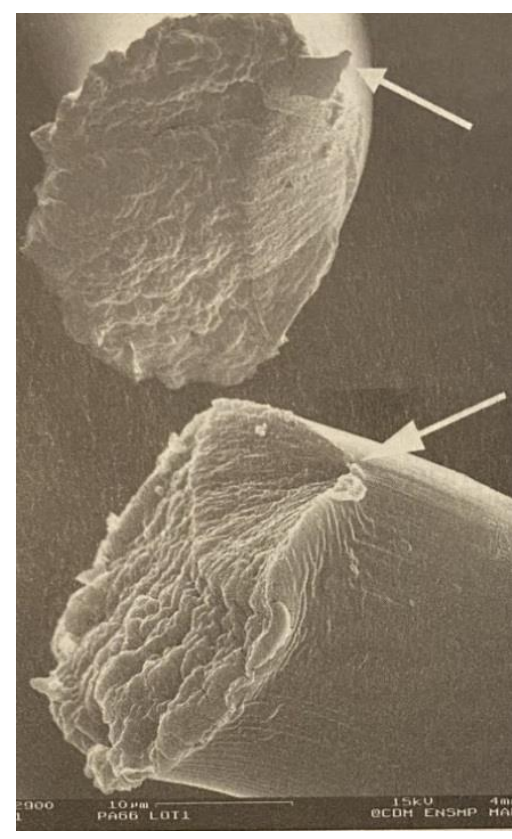

Slika 1. Odgovarajući krajevi vlakna polimera PA66 nakon otkaza nastala zatezanjem, na sobnoj temperaturi, gde strelica pokazuje oblast nastanka pukotine, poprečni presek vlakna na početku je $27 \mu \mathrm{m}$

\section{EFEKTI ODNOSA STRUKTURE I SVOJSTVA NA OTKAZ I ZAMOR PRIRODNIH VLAKANA}

Karakteristika zamora materijala se definiše kao otkazivanje ili propadanje mehaničkih osobina nakon ponovljene primene opterećenja. Zamor vlakana se pojavljuje kada se vlakno konstantno izlaže opterećenju koje je manje od nivoa potrebnog da prouzrokuje otkaz materijala nakon samo jednog izlaganja opterećenju. Ovaj manji nivo opterećenja, koji može da bude u obliku zatezanja, pritiska, ili oba, možda nije dovoljno jak da pokida vlakno, ali akumulacija opterećenja iz svakog opterećenog/rasterećenog ciklusa može da rezultuje eventualnim kidanjem vlakna. Tekstilna vlakna su u svojoj praktičnoj upotrebi skoro uvek predmet opterećenja i deformacije. Zatezanje, savijanje, trošenje i uvijanje vlakana koje se ponavljaju su česte radnje tokom obrade vlakana i dovođenja proizvoda do krajnje upotrebe, što prouzrokuje otkaze usled zamora materijala.

Studije zamora vlakana se mogu sprovesti u tri različita vida deformacije: zatezni, uvojni i savojni. BTA test (određivanje dozvoljenog ugla uvijanja) se može smatrati kombinacijom tri modela, barem zateznog i uvojnog. Vlakno prečnika D se fiksira između dve spone, na dužini $l$, a zatim se uvija dok vlakno ne pukne. BTA se dobija sledećom jednačinom:

$$
B T A=\tan ^{-1}\left(\frac{1}{\pi D r}\right)
$$

gde je $r$ broj obrtaja na vlakno pre nego što pukne.

U radu [6] je objavljeno da među vezama Gossypium Barbadense pamuka, postoji negativna linearna povezanost $(r=-0,59)$ između BTA i veka trajanja zamora usled savijanja vlakna, i krutosti vlakna pamuka, kao što je indikovano da je BTA bio nezavisan od finoće vlakna, debljine zida i stepena zrelosti. Vlakna pamuka duge drške su imala više BTA vrednosti i veću čvrstoću, ali manje izduženje. Materijal koji je krt obično ima osobinu relativno kratkog izduženje pucanja. Sposobnost materijala da preživi deformaciju uvijanjem je indikacija krutosti. Stoga, povećani BTA ukazuje na nižu krutost i duži vek trajanja zamora. Drugim rečima, među varijantama pamuka koje su ispitane, dugačak pamuk je krt i lako se optereti na zamor u poređenju sa vlaknima pamuka srednje dužine.

U radu [7] su ispitivani BTA i životni vek različitih tipova vlakna na savijanje. Tabela 1 . pokazuje rezultate vune $\mathrm{i}$ pamuka. Može se videti da su BTA vrednosti pamuka više nego kod vune, što ukazuje na to da pamuk ima veću krutost od vune. Prosečni vek na savijanje u tabeli 1 . potvrđuje ovaj zaključak.

Tabela 1. Prosečni vek na savijanje i BTA vlakana pamuka i vune na $65 \%$ RH i $21^{\circ} \mathrm{C}$

\begin{tabular}{|c|c|c|c|}
\hline Vlakno & $\begin{array}{c}\text { Prosečni vek trajanja } \\
\text { fleksibilnosti } \\
\pm \text { standardna greška } \\
\text { (x 1000) }\end{array}$ & Prečnik & $\begin{array}{c}\text { BTA } \\
\left({ }^{\circ}\right)\end{array}$ \\
\hline Vuna & $148.0 \pm 24.0$ & 26 & 44.69 \\
\hline $\begin{array}{c}\text { Neočišćeni pima S- } \\
5 \text { pamuk }\end{array}$ & $9.0 \pm 1.0$ & 11 & 64.17 \\
\hline $\begin{array}{c}\text { Mercerizovana } \\
\text { pima }\end{array}$ & $14 \pm 3.0$ & 11 & 64.74 \\
\hline $\begin{array}{c}\text { Očišćeni deltapine } \\
\text { pamuk }\end{array}$ & $17.0 \pm 4.0$ & 12 & 61.88 \\
\hline $\begin{array}{c}\text { Mercerizovan } \\
\text { deltapine }\end{array}$ & $19.00 \pm 3.0$ & 14 & 64.74 \\
\hline
\end{tabular}

\section{ASPEKTI ŽIVOTNE SREDINE NA ZAMOR}

U bilo kojoj diskusiji efekata životne sredine na otkaz izazvan zamorom, potrebno je ispitati tri moguće interpretacije termina. Prvi od ovih je uzimanje u obzir kako životna sredina utiče na mogućnost otkaza, drugi se bavi načinom na koji otkaz utiče na životnu sredinu, a treći je uzimanje u obzir kako efekti otkaza izazvanog zamorom na životnu sredinu mogu biti smanjeni.

U ovom poglavlju, pretpostavka je da je termin ,životna sredina" sveobuhvatan za celu planetu, zajedno sa njenim mineralnim i biološkim stanovnicima, i koji uključuje prateći atmosferski omotač do mesta na kojoj gravitaciona sila više ne vezuje supstance $u$ blizini Zemlje. Nema poente, na primer, pretpostavljati da oslobađanje gasova $u$ stratosferu neće imati efekta na planetu, zato što se baš u ovom predelu dešava efekat staklene bašte koji je odgovoran za globalno zagrevanje.

Uticaj toplote, drugačijeg tipa radijacije, se takođe ne sme ignorisati. Termalno razaranje, često može biti početni faktor oštećenja vlakana nastavljajući velikom brzinom. Bukvalno, sva vlakna trpe manje promene, kao što su diskoloracija, smanjivanje, na približno malim temperaturama. Mnogi od tih, primetno ona celulozna, značajnije su podložne toploti, često počinju da gore, što ih čini opasnim u domaćinstvima gde se može susresti izloženost otvorenom plamenu.

Termalna degradacija sama po sebi, bez sagorevanja je uzrok promena $\mathrm{u}$ mehaničkom smislu. $U$ radu [8] je utvrđeno da najlonska vlakna gume češće otkazuju usled puzanja na povišenim temperaturama. Kod kompozita, efekti životne sredine na degradaciju vlakna se istražuju za 
vlakna silikon karbida koji se koristi kao materijal za ojačavanje na temperaturama od $450{ }^{\circ} \mathrm{C}$, sa indikacijom da izlaganje vazduhu ima značaj efekat, što povećava mogućnost otkaza, u poređenju sa uslovima vakuuma. Jačanje vlakna stakla u opsegu od 20 do $160{ }^{\circ} \mathrm{C}$ je istraživano u radu [9], gde je uočeno da otkaz omotača fenolnog sistema nije pod uticajem temperature, ali se pojavljuje slabljenje epoksidnog sistema. U radu [10] istražuju se promene koje se dešavaju na kriogenim temperaturama, u super provodnim magnetnim zavojnicama epoksidnih izolatora od ojačanog stakla i beleže da rezultati ukazuju na jak uticaj smera vetra i izlaganja radijaciji. Koriste se ojačane epoksidne mešavine vlakana ugljenika, i uočavaju da se zamorna snaga značajno smanjuje kako se temperatura podiže.

\section{OŠTEĆENJE USLED ZAMORA KOD STRUKTURALNIH TEKSTILNIH KOMPOZITA: TESTIRANJE I STRATEGIJE MODELOVANJA}

U ovom poglavlju se diskutuje o zamoru strukturalnih tekstilnih kompozita, gde su tekstilne niti ugrađene $\mathrm{u}$ plastičnu matricu radi unapređenja njenih mehaničkih karakteristika. Većina dosadašnjih poglavlja se bavila zamorom suvih, neimpregniranih tekstilnih niti, dok je ovde struktura tekstilnih vlakana impregnirana smolom i dovedena do čvrstog stanja. Primena tih strukturalnih tekstilnih kompozita se može naći u mnogim industrijskim oblastima, počevši od automobilske industrije, industrije turbina i vazduhoplovstva do sportske industrije.

\subsection{Međusobno dejstvo vlakna/matrice}

Kvalitet međusobnog dejstva vlakna/matrice je veoma kritična karakteristika za učinak zamora. Generalno uzevši, prianjanje između vlakna i matrice je bolja za termo-reaktivne matrice nego za termo-plastične matrice, jer visoka viskoznost termo-plastičnih smola čini impregnaciju ojačavanja vlaknima težom.

Fina obrada površine se skoro uvek primenjuje na vlaknima kako bi se dozvolilo rukovanje sa minimalnom štetom, ali i kako bi se učvrstila veza vlakna/matrice. Kod upotrebe ugljenikovih i aramidnih vlakana u kompozitnim primenama, fina obrada površine ili primenjena veličina uglavnom obavljaju obe funkcije. Fina obrada se primenjuje na vlakno u momentu proizvodnje vlakna, i na vlaknu kroz ceo proces konverzije u tkaninu. Predivo staklenih vlakana se, međutim, tretira u dve faze prilikom upotrebe za tkanje. Prva fina obrada se primenjuje $u$ momentu proizvodnje vlakna na prilično visokom nivou, a služi isključivo za zaštitu vlakna od štete tokom rukovanja i samog procesa tkanja. Ova zaštitna fina obrada, koja se često zasniva na štirku, se čisti tj. „,izriba“ nakon procesa tkanja uz pomoć toplote ili hemikalija. Oribana istkana tkanina se potom odvojeno tretira sa različitim finim obradama kompatibilnim za matrice koje su posebno osmišljene da prilagode vlakna kontaktnim karakteristikama smole kao što su čvrstoća vezivanja, vodootpornost i optička jasnoća.

\subsection{Zamor zatezanje-zatezanje}

Najviše korišćen test zamora je jednoosni test zamora zatezanje-zatezanje. Geometrija je uzorak sa paralelnim stranama, opremljen sa jezičcima. Izbor materijala jezičaka varira među laboratorijama za ispitivanje. Neke preferiraju čelične ili aluminijumske jezičke, dok većina laboratorija koristi staklene/epoksid jezičke, gde ojačanje staklom ima $\left[+45^{\circ} /-45^{\circ}\right]$ ns redosled slaganja. U većini slučajeva, jezičci su ravnih strana i nisu suženi.

Ispitivanje zamora se uglavnom sprovodi pomoću servohidraulične mašine, koja je opremljena sa hvataljkama koje učvršćuju uzorak. Poravnanje uzorka je veoma važno. Ne smeju se izazvati opterećenja savijanja zbog lošeg poravnanja. Opterećenje se registruje pomoću ćelije opterećenja, dok ekstenzometar registruje aksijalno naprezanje. Takođe se registruje deformacija na mestu zahvatanja uzorka, ali to nije vrlo korisno. Poprečna deformacija se može izmeriti mernom trakom ili biaksijalnim ekstenzometrom. Termo-elementom se može nadzirati površinska temperatura kompozita. Frekvencija ispitivanja je uvek izabrana najviša moguća kako bi se ograničilo trajanje testa i trošak sveo na minimum, ali zamor nekih kompozita najviše zavisi od frekvencije (posebno u slučajevima vlaknima ojačane termo-plastike).

$\mathrm{U}$ ispitivanjima zamora zatezanje-zatezanje, odnos napona $\mathrm{R}$ se često bira da bude 0,1 . Ipak, odnos napona (ili srednji napon) takođe ima jasan efekat na stopu rasta oštećenja kod zamora zatezanje-zatezanje.

$$
R=\frac{\sigma_{\min }}{\sigma_{\max }}
$$

gde je:

$\sigma_{\min }$ minimalna vrednost napona, a
$\sigma_{\max }$ maksimalna vrednost napona.

Mnogi autori su pokazali da ukoliko se maksimalni napon drži konstantnim, rast oštećenja se smanjuje zbog povećavajuće srednje snage. Proučavan je razvoj oštećenja zamorom u ugljenik/epoksid laminatima. Utvrđeno je da je broj pukotina matrice u unakrsno slojevitim laminatima bio značajno manji ako je odnos napona povećan od $\mathrm{R}=0.03$ do $\mathrm{R}=0.5$. Ovaj fenomen nastaje usled zatvaranja pukotine. Tokom rasta pukotina od $90^{\circ}$, stvara se otpadak materijala između površina pukotina. Kada se pukotina zatvara, ovaj višak materijala prouzrokuje: (i) pritisne sile u slojevima od $90^{\circ}$, za upravne pukotine, ili (ii) klizne sile, za ugaona oštećenja matrice. Za ispitivanje zamora sa povećanim odnosom napona, pukotine će ostati otvorene i neće se formirati dodatne pukotine na nivou niskog napona. Nekoliko autora su dobili slične rezultate. Predstavljeni su reprezentativni podaci o zamoru, u obliku Gudman dijagrama, za nekoliko jednosmernih kompozita na $10^{7}$ ciklusa. Ako se odnos napona $\mathrm{R}$ povećava, maksimalni napon može biti veći za isti vek trajanja zamora.

Ako se meri poprečno izduženje, takođe se može pratiti Poasonov odnos $v_{x y}$. Nedavno je pokazano da je evolucija Poasonovog odnosa veoma osetljiv parametar oštećenja zamorom. Slika 2 pokazuje evoluciju Poasonovog odnosa za jednosmerni stakleni tekstilni/epoksid kompozit tokom zamora zatezanje-zatezanje. Krive $v_{x y}-\varepsilon_{x x}$ u zamoru sa kontrolisanom deformacijom između 0.0006 (0.06\%) i $0.006(0.6 \%)$ pokazuju veoma nelinearno ponašanje i sa gornje strane su ograničene statičkom degradacijom Poasonovog odnosa. 


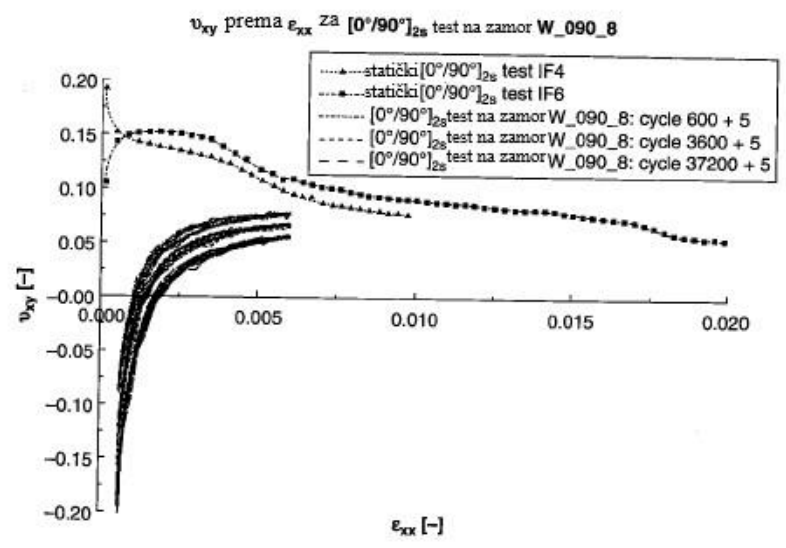

Slika 2. Evolucija Poasonovog odnosa za jednosmerni stakleni tekstil/epoksid kompozit tokom zamora zatezanjezatezanje

\section{ZAKLJUČAK}

Trenutno, postoje alatke za simulaciju zamora koje predviđaju gustinu pukotina $\mathrm{u}$ jednom sloju jednosmernih vlakana ili predviđaju degradaciju homogenizovanih elastičnih osobina UD-zasnovanog laminata. Međutim, nijedna od ovih alatki za simulaciju ne može da premosti jaz između pojave mikro-mehaničkog oštećenja i strukturalnog odgovora oštećenog laminata. Štaviše, premalo studija je urađeno na temu ponašanja zamora kod kompozita sa tekstilnom osnovom.

Pristup koji obećava rešavanje ovih problema jeste modelovanje na više nivoa, koje omogućava uključivanje osobina mezoskopskog ponašanja u makroskopskom opisu, bez potrebe za prethodno zahtevanim makroskopskim konstitutivnim zakonom. Makroskopski konstitutivne veze (osobine materijala na nivou laminata) se dobijaju pojačavanjem modelovanja materijala na nižim razmerama (mezo- i mikro-), gde je predstavljena detaljna struktura materijala sa njegovim specifičnim ponašanjem. Pristup sa više razmera povezuje prednosti čisto mezo- ili mikromehaničkog pristupa sa prednostima čisto makromehaničkog modelovanja. Kompleksno ponašanje materijala se pravilno detektuje modelovanjem na niskim razmerama, dok analize na velikim razmerama (makrorazmere) ostaju numerički izvodljive.

\section{LITERATURA}

[1] J.W.S. Hearle, B. Lomas, W.D. Cooke, „Atlas of fibre fracture and damage to textiles" 2 nd edition, CRC Press, Boca Raton, Florida, 2000, ISBN: 0-8493-3881-6.

[2] M.S. Ellison, S.H. Zeronian, ,Breaking-twist angle and crosslinking in wool fibers under alkaline conditions as a function of temperature“, Textile Reseasch Journal vol. 48(12), pp. 692-697, December 1987, ISSN: 1746-7748, DOI:10.1177/ 004051757804801203.

[3] M.M. Kamal, S.H. Zeronian, M.S. Ellison, A.H. Hyer, „Selected single fiber mechanical properties of different gossypium barbadense cotton varieties", Textile Reseasch Journal vol. 54(5), pp. 343-350, May 1984, ISSN: 17467748, DOI:10.1177/ 004051758405400511.

[4] K. Slater, „Comfort Properties of Textiles“, Textile Progress vol. 9 (4), pp. 1-70, 1977, ISSN: 17542278, DOI: 10.1080/00405167.1977.10750095.
[5] N.L. Hancox, „High performance composites with resin matrices", In: Kelly, A. and Mileiko S.T. (eds), Fabrication of Composites, Handbook of Composites vol. 4, pp. 1-44, January 1983, Amsterdam, North Holland, ISBN: 0444864474.

[6] M.M. Kamal, S.H. Zeronian, M.S. Ellison, A.H. Hyer, „Selected single fiber mechanical properties of different gossypium barbadense cotton varieties", Textile Research Journal vol. 54(5), pp. 343-350, May 1984, ISSN: 00405175, DOI:10.1177/ 004051758405400511.

[7] M.S. Ellison, S.H. Zeronian, K.W. Alger, S.M. Aboul-Fadl, T.M. Soler, ,Interrelationships between selected mechanical properties of individually-tested polymeric fibers", Polymer Engineering and Science vol. 29(24), pp. 1738-1745, December 1989, ISSN: 1548-2634, DOI: 10.1002/pen.760292405.

[8] L.C. Nkiwane, „High temperature creep performance of nylon 6.6 tyre cords“, Kautschuk Gummi Kunststoffe vol. 54(12), pp. 648, 2001, ISSN: 0948-3276.

[9] J.M. Hale, A.G. Gibson, S.D. Speake, „Biaxial Failure Envelope and Creep Testing of Fibre Reinforced Plastic Pipes in High Temperature Aqueous Environments“, Journal of Composite Materials vol. 36(3), pp. 257-270, February 2002, ISSN: 00219983, DOI: 10.1177/ 0021998302036003516

[10] K. Bittner-Rohrhofer, K. Humer, H.W. Weber, Cryogenics vol. 42(5), pp. 265-272, 2002, ISSN: 0011-2275, DOI: 10.1016/S0011-2275(02)00039-5.

\section{Kratka biografija:}

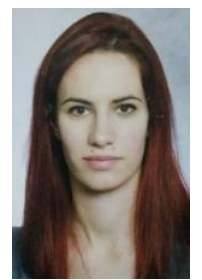

Ružica Sovilj rođena u Rumi 1991. godine. Osnovne studije na Fakultetu tehničkih nauka, oblast: mehanizacija i konstrukciono mašinstvo, završila 2017. godine. Zaposlena u STŠ »Milenko Brzak - Uča« u Rumi. Majka dvoje dece.

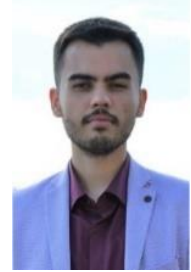

Nikola Ilanković rođen u Subotici 1994. god. Masterirao 2018. godine na Fakultetu tehničkih nauka. Zaposlen kao asistent master na Fakultetu tehničkih nauka u Novom sadu. 